\title{
"Carbon market. The future investment of sustainable development in developing countries: climate smart investment"
}

\begin{tabular}{ll} 
AUTHORS & Hesham Elsayed Eissa \\
\hline ARTICLE INFO & $\begin{array}{l}\text { Hesham Elsayed Eissa (2017). Carbon market. The future investment of } \\
\text { sustainable development in developing countries: climate smart investment . } \\
\text { Environmental Economics, 8(3), 62-69. doi:10.21511/ee.08(3).2017.06 }\end{array}$ \\
\hline DOI & http://dx.doi.org/10.21511/ee.08(3).2017.06 \\
\hline RELEASED ON & Monday, 11 September 2017 \\
\hline RECEIVED ON & Saturday, 15 July 2017 \\
\hline ACCEPTED ON & Monday, 21 August 2017 \\
\hline LICENSE & (cc) EY-Nc \\
\hline JOURNAL & This work is licensed under a Creative Commons Attribution-NonCommercial 4.0 \\
\hline ISSN PRINT & "Environmental Economics" \\
\hline ISSN ONLINE & $1998-6041$ \\
\hline PUBLISHER & $1998-605 X$ \\
\hline FOUNDER & LLC “Consulting Publishing Company "Business Perspectives" \\
\hline LLC “Consulting Publishing Company "Business Perspectives"
\end{tabular}

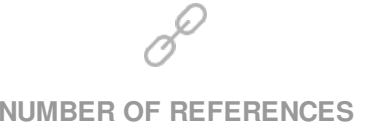

12
NUMBER OF FIGURES

1
NUMBER OF TABLES

1

(C) The author(s) 2023. This publication is an open access article. 


\title{
Hesham Elsayed Eissa (Egypt) \\ Carbon market. The future investment of sustainable development in developing countries: climate smart investment
}

\begin{abstract}
There is no doubt that the problem of climate change has become imperative for all parties oa the international community to join forces to resolve this crisis. With the signing of the Paris Agreement and following many deliberations and negotiations, this agreement is a new phase in dealing with the reduction of greenhouse gas emissions. With the participation of everyone, whether developed or developing countries, that opens the door to a new system of investment in the implementation of this commitment.

Article 6 of the Paris Agreement is the cornerstone of this new type of emissions exchange between the parties. The old emissions trading system under the Kyoto Protocol has shown many advantages and disadvantages, which open the door to the need to find a new system that achieves the actual emission reduction target and opens the way for a new type of FDI.

Although the features of the new system have not yet been formed, but many of the ideas and theses dealt with by many intellectuals and economists on how to develop an emissions trading system that achieves the goals of sustainable development.

In this paper, a new vision will be taken to put Article 6 of the Paris Agreement into effect, in order to achieve the objective of the main agreement which is to reduce emissions without having a significant impact on development plans, especially in developing and poor countries, on the one hand, and the opportunity to attract foreign investment and capital flows towards more attention to the green economy.
\end{abstract}

Keywords: climate change, clean development mechanism, greenhouse gas, sustainable development goals, special economic zones.

JEL Classification: Q01, Q54.

Received on: $15^{\text {th }}$ of July, 2017.

Accepted on: $21^{\text {st }}$ of August, 2017.

\section{Introduction}

The Paris Agreement of Climate Change is one of the most controversial agreements in the current period. It has radically changed the concept of bearing the burden of reducing greenhouse gases from developed countries only, as historically responsible for global warming, so that all parties in the international community, both developed and developed, are committed to bearing the burden of reducing emissions. The negotiations before the Paris agreement at the end of 2015 took a long and arduous path, beginning with the Conference of the Parties in Doha in Qatar in 2012, ending at the Conference of the Parties in Paris.

The most important point of contention between developed and developing countries is the need for developed countries to provide support in various forms, whether financial or technical,

(C) Hesham Elsayed Eissa, 2017.

Hesham Elsayed Eissa, Head of Qualitative Council of Climate Change \& Sustainable Development, Arab Council of Green Economy, Egypt.

This is an Open Access article, distributed under the terms of the Creative Commons Attribution-NonCommercial 4.0 International license, which permits re-use, distribution, and reproduction, provided the materials aren't used for commercial purposes and the original work is properly cited. appropriate to developing countries to be able to meet the commitment to reduce greenhouse gases. One of the most important mechanisms in this framework was the possibility of exchanging emissions among countries to meet emission reduction commitments in so-called carbon markets as stated in Article 6 of the Agreement, the Para 1: "Parties recognize that some Parties choose to pursue voluntary cooperation in the implementation of their nationally determined contributions to allow for higher ambition in their mitigation and adaptation actions and to promote sustainable development and environmental integrity" 1 .

The climate change agreement has gone through many stages, beginning with the Climate Change Climate Agreement of 1992 at the Rio de Janeiro Earth Summit and the Bali Action Plan in 2007, which established the principle of voluntary participation of developing countries in emission reduction efforts.

In 2011, during the Conference of the Parties in Durban South Africa, the Durban Platform for Action was adopted to prepare a new agreement

${ }^{1}$ UNFCCC, Paris Agreement, 2015. www.unfccc.int 
to be signed in Paris in 2015 to adopt a new regime that includes commitments to reduce greenhouse gases in all developing and developed countries.

The question here is how developing countries with economic and social problems and plans for economic reform that require further development can meet their commitments to reduce greenhouse gases, at a time, when they want more economic activities? In addition, the adoption of the principles of sustainable development of 17 socioeconomic and environmental objectives also requires the adoption of new systems of development and claims further flow of funding and investment, which means the need to search for new approaches to deal with these goals.

The Paris Agreement, in its Article 6 above, was adopted as a reference to the creating a new emissions trading system that can contribute to developing countries' implementation of greenhouse gas reduction commitments and this is the topic of this research.

The research methodology is based on the descriptive approach and the analytical and historical method. The research will be a descriptive case for the carbon markets, especially the mechanisms used through the historical presentation of the carbon markets, which is the Kyoto Protocol, and then the analytical approach which explains the research target and expected returns for the use of carbon markets.

The research problem is that since the beginning of 2012 - the end of the first commitment period of the Kyoto Protocol, there is no clear and consistent mechanisms for managing emissions reduction commitments.

\section{Climate change and sustainable development}

There is a dual relationship between sustainable development and climate change. On the one hand, climate change influences key natural and human living conditions and thereby also the basis for social and economic development, while on the other hand, society's priorities on sustainable development influence both the GHG emissions that are causing climate change and the vulnerability ${ }^{2}$.

\footnotetext{
${ }^{2}$ IPCC, The dual relationship between climate change and Sustainable Development. www.ipcc.ch
}

The wide ranging of potential impacts of climate change on sustainable development and vice versa, suggest that the linkages between these two topics need to be critically analyzed. Such an analysis was attempted in the IPCC third assessment report (TAR), and while some progress was made, the work was incomplete ${ }^{3}$.

In 2008, Angel Gurría, OECD Secretary-General said: "Climate change involves all three dimensions of sustainable development: the economic, the environmental and the social dimension. Addressing this challenge demands a long term perspective on how our actions today will affect the lives of our children, and it also demands a dialogue with all stakeholders involved in order to reach viable solutions" .

This relationship began when Article 4 of the Framework Convention on Climate Change in 1992 stipulated that developed countries shall help developing countries achieve balanced growth and sustainable development. The Kyoto Protocol also included in Article 12 the use of part of the proceeds from the sale of CDM project certificates to achieve sustainable development in developing countries. Finally, Article 6 of the Paris Climate Change Agreement provided for sustainable development in developing countries through voluntary carbon exchange mechanisms. On the other hand, the 17 sustainable development goals included Goal 13 on addressing climate change directly. While other goals related to energy and sustainable cities indirectly included the issue of climate change, particularly regarding mitigation.

Based on the above, it is clear that the relationship between sustainable development and climate change is a complex relationship, which makes it difficult to determine which is the variable and which is dependent in the development equation.

The problems of providing finance are one of the main obstacles facing the international community to deal with climate change and sustainable development issues.

Because of that, the 2030 Agenda for Sustainable Development and the Paris Agreement represent the

\footnotetext{
Mohan Munasinghe, Chairman, Munasinghe Institute for Development (MIND), Climate change and sustainable development linkages: points of departure from the IPCC TAR, 2009.

${ }^{4}$ OECD, Seminar on "Sustainable Development and Climate Change: International and National Perspectives", 2008. http://www.oecd.org/newsroom/seminaronsustainabledevelopmentandcl imatechangeinternationalandnationalperspectives.htm
} 
most ambitious multilateral goals ever set. These goals require an unprecedented mobilization of both public and private finance - some US $\$ 90$ trillion over the next 15 years. Public finance is scarce and must serve competing priorities. Progress has been made to mobilize private finance by shaping the right enabling investment conditions and crowding-in private capital with public funds ${ }^{5}$.

But in the end, this problem remains a major obstacle to achieving the target.

The question is whether the negative effects of greenhouse gas reduction on the development aspirations of developing countries and what the proposals for a solution to this problem?

1.1. Impact of greenhouse gas reduction commitments on developing countries. Climate change mitigation effect can be measured as an economic cost. Many studies have been conducted on the environmental impacts of climate change, however the socio-economic impact still to be properly assessed. Transfer of the latest modelling capabilities related to addressing this issue is needed to obtain more accurate projections. This will enable better analysis of the related effects and the formulation of appropriate mitigation mechanisms.

The economic impacts of emission reduction costs must be one of the most important factors to be considered when economic models are used to estimate expected growth trends, as the most of these indicators do not consider the effects of environmental degradation in general on the real growth of GDP ${ }^{6}$.

On the other hand, when talking about the mitigation effort, mitigation involves some level of co-benefits and risks, but these risks do not involve the same possibility of severe, widespread and irreversible impacts as risks from climate change. Inertia in the economic and climate system and the possibility of irreversible impacts from climate change increase the benefits from near-term mitigation efforts (high confidence). Delays in additional mitigation or constitutions on technological options increase the longer-term mitigation costs to hold climate change risks at a given level ${ }^{7}$. The costs of avoiding emissions of carbon dioxide, the principal greenhouse gas, depend on substitution possibilities on several margins:

- the ability to substitute across different fuels (which release different amounts of carbon dioxide per unit of energy);

- to substitute away from energy in general in production;

- and to shift away from energy-intensive goods.

\section{Carbon mechanisms between past and future}

Carbon markets are one of the mechanisms that were used during the period 2006 to 2012 significantly in the reduction of greenhouse gases. The Kyoto Protocol was the agreement that regulated the work of these mechanisms both at the level of developed and developing countries through the regulation of emissions exchange.

In fact, by analyzing the results of the previous emissions exchange experience, there are many advantages as well as many of the problems encountered in the expansion of this mechanism. The number of projects registered in the International Council of the Climate Change Convention as projects of a clean development mechanism around 7776. Project has contributed to the reduction of about 2.8 billion tons of carbon dioxide equivalent over 10 years.

China ranked first in the list of countries that implemented these projects by more than $80 \%$ of the total of these projects, followed by India and Brazil ranked ${ }^{8}$.

CDM mechanisms has mobilized USD 215 billion of investment in developing countries. Of this amount, USD 92.2 billion - roughly equivalent to the combined foreign direct investment in Denmark, France and Germany in 2007-2011 - is already invested ${ }^{9}$.

\footnotetext{
5 Peter Thomson, President of the $71^{\text {st }}$ session of the UN General Assembly, UNEP, Financing sustainable development, moving from momentum to transformation in a time of turmoil, 2012

${ }^{6}$ Methodology for Integrated Environmental-Economic Analysis of GDP and Productivity, University of Minnesota, 2010.
}

${ }^{7}$ Climate Change 2014 Synthesis Report Summary for Policymakers, IPCC, 2014.

${ }^{8}$ UNFCCC, CDM Project. http://cdm.unfccc.int/Projects/projsearch.html

9 Dr. Adam Bumpus, Fruitful design: the CDM. https://cdm.unfccc.int/about/dev_ben/CDM-Benefits-2012 


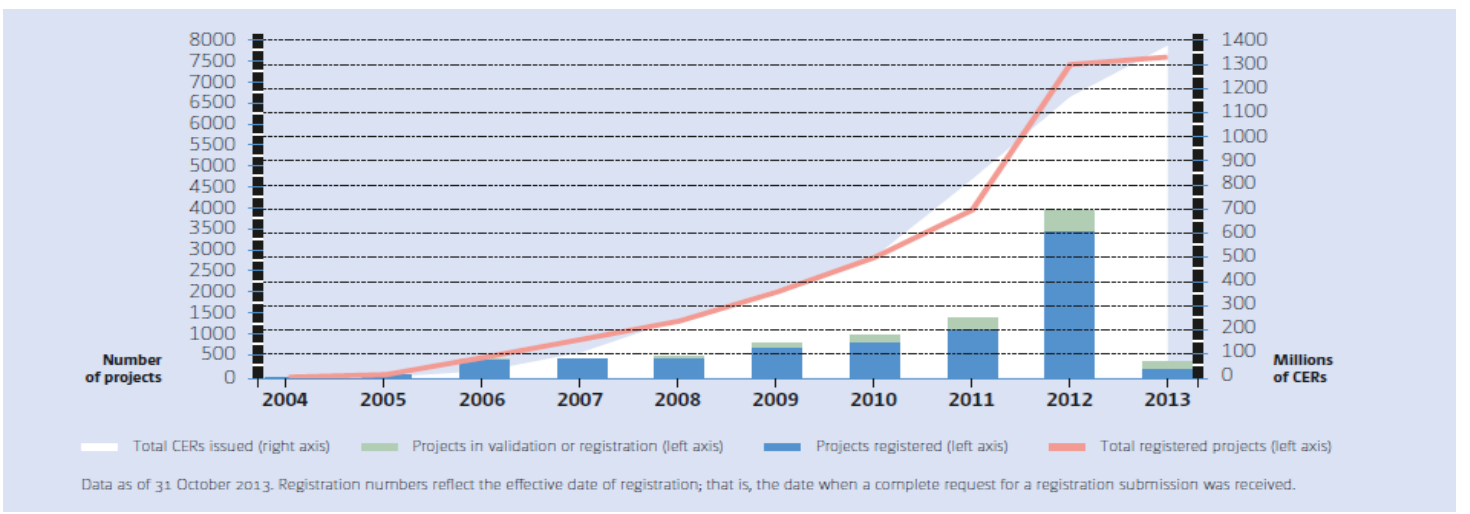

Fig. 1. Certified emission reductions issued cumulative, projects registered cumulative, and ptojects registered, registering and in validation by year, 2004-2013 ${ }^{10}$

Despite these positive impacts of the emissions trading mechanism during the previous phase, however, there are many difficulties encountered in implementation, especially in developing countries (except China, India and Brazil), for example, weak promotion of this type of project, administrative and legal obstacles and incompatibility of local laws with this new mechanism, also weak technical capacity in these countries to deal with these projects.

On the other hand, by the end of 2012, the rate of purchase of certificates of carbon reduction resulting from these projects was reduced, which led to the cost of implementing projects became more than the return on investment. Also there are many studies that have questioned the existence of accounts to reduce the same projects more than once (double counting).

As of 2012, despite the agreement of the member states of the Framework Convention on Climate Change to extend the Kyoto Protocol for a second period ending in 2020, however, the reality has proved that implementation has not happened and has led to the collapse of the mechanisms of exchange of emissions, especially $\mathrm{CDM}$, in anticipation of what will happen after the Conference of the Parties in Paris in 2015.

Between 2013 and 2015, negotiations between developing and developed countries were focused on supporting developing countries to implement their commitments to reduce greenhouse gases, in a way that does not contradict the development aspirations of these countries.

On the other hand, the negotiations on the goals of sustainable development have begun to lay the foundations for achieving these goals and set target

\footnotetext{
${ }^{10}$ Executive Board, annual report, Clean Development Mechanism, UNFCCC, 2013, p. 4.
}

No. 17, which is active in activating international partnerships and financing for sustainable development, here, the climate change agreement met the goals of sustainable development in Article 6 of the Convention on Climate Change, which included the need to overcome the previous negatives in the mechanisms of exchange of emissions as follows:

- Parties shall, where engaging on a voluntary basis in cooperative approaches that involve the use of internationally transferred mitigation outcomes towards Nationally determined contributions, promote sustainable development and assurance Environmental integrity and transparency, including in governance, and shall apply Robust accounting to ensure, inter alia, the avoidance of double counting, consistent With guidance adopted by the Conference of the Parties serving as the meeting of The Parties to this Agreement ${ }^{11}$.

- A mechanism to contribute to the mitigation of greenhouse gas emissions and support sustainable development is hereby established under the authority and guidance of the Conference of the Parties serving as the meeting of the Parties to this Agreement for use by Parties on a voluntary basis ${ }^{12}$.

From the above, it is clear that emissions trading mechanisms are one of the tools for achieving sustainable development through the implementation of greenhouse gas reduction commitments and in line with Goal 13 of sustainable development goals, on the one hand. It also provides additional sources of funding through emission sharing mechanisms, on the other hand.

\footnotetext{
${ }^{11}$ Paris Agreement, article 6, para 2

${ }^{12}$ Paris Agreement, article 6, para 4
} 
Also, the Paris Convention stipulated that all countries should submit national emission reduction plans National Determined Contribution (NDC), therefore one of the implementation tools for that is carbon market.

Hence, it is possible to say that the need to develop new types and forms of investments that depend on achieving sustainable development, on the one hand, as well as increasing capital flows and achieving profits on the other hand.

On the other hand, the average growth rate of gross domestic product (GDP) in the European countries is not more than $2 \%$ between 2012 and 2016. Some attributed the decline in this rate to the saturation of the European market, on the one hand, and the low rates of population growth, on the other hand, which means saturation of European markets, and here emerged the need to invest in emerging markets in developing countries.

\section{Climate smart investment}

Carbon market mechanisms are becoming an increasingly popular instrument for international and domestic climate change mitigation efforts. In particular, national and sub-national programs have shown significant growth in recent years, going some way to make up for uncertainty of international markets under the Kyoto Protocol.
Moreover, the 2015 Paris Agreement established a new market mechanism to assist Parties in achieving nationally determined contributions (NDC), raising ambition and supporting sustainable development. The exact rules of this mechanism are yet to be determined.

Therefore, a need to adopt new mechanisms to implement greenhouse gas reduction commitments as well as financing for sustainable development, the need to exploit foreign direct investment flows from developed to developing countries has become important to finance sustainable development on the one hand and to implement greenhouse gas reduction on the other. In this regard, carbon exchange mechanisms are one of the most important mechanisms.

In preparation for the next meeting (COP) conference of Parties in Germany in November 2017, the Group of African Negotiators (AGN) expressing the developing countries held meeting in Mali state from 15-18/7/2017, to discuss the unification of negotiating concepts and the positions of developing countries in the coming negotiations. The meeting resulted in the existence of some conflicting positions between developing and developed countries, which are shown in the Table 1 (so far the final document of the meeting has not been issued).

Table 1. The meeting resulted in the existence of some conflicting positions between developing and developed countries

\begin{tabular}{|l|l|l|}
\hline \multicolumn{1}{|c|}{ Topic } & \multicolumn{1}{|c|}{ Developed countries } & \multicolumn{1}{c|}{ Developing countries } \\
\hline $\begin{array}{l}\text { The link between SDG fund and } \\
\text { climate fund }\end{array}$ & $\begin{array}{l}\text { The difference on funding allocations for each of them as funding } \\
\text { for sustainable development is ODA to finance development plans } \\
\text { from climate finance. }\end{array}$ & $\begin{array}{l}\text { The need to link the sources of funding to the two } \\
\text { objectives and to be in accordance with the objective 17 } \\
\text { of sustainable development. }\end{array}$ \\
\hline Reduction commitments & $\begin{array}{l}\text { The need for numerical commitments to be specific, ambitious and } \\
\text { measurable and not to calculate previous reduction efforts within } \\
\text { the plans to be submitted. }\end{array}$ & $\begin{array}{l}\text { Commitments can be made in the form of plans and } \\
\text { targets in the first phase, taking into account previous } \\
\text { reduction efforts calculated in future plans as they have } \\
\text { already been made. }\end{array}$ \\
\hline Carbon market & $\begin{array}{l}\text { Prefer to be a carbon tax or a carbon pricing with the possibility of } \\
\text { exchange reduction according to each country or group of } \\
\text { countries voluntarily. }\end{array}$ & $\begin{array}{l}\text { The situation is not clearly defined for the different } \\
\text { visions among developing countries themselves. }\end{array}$ \\
\hline Financing mechanisms & $\begin{array}{l}\text { The need for the participation of developing countries, especially } \\
\text { rich ones, in providing funding for the Green Climate Fund. }\end{array}$ & $\begin{array}{l}\text { Funding from developed countries should be limited to } \\
\text { funding for the Green Climate Fund. }\end{array}$ \\
\hline
\end{tabular}

Source: meeting with The delegate of Egypt who attended the conference, who reported the data in this table

It can be said in this context that the carbon market must be based on investment incentives between the two parties and through the exchange of emissions and investment flows to reduce greenhouse gas measures and to the benefit of all parties.

The first step from the writer's point of view was the analysis of article 6 of Paris agreement, that groups together issues that had originally been spread over a number of articles both in drafts of the PA, as well in drafts of the COP Decision. So Scope of Article 6 in Paris Agreement are:
1. Cooperative approaches (Paragraph 6.1). This paragraph covers the general concept that Parties may choose, on a voluntary basis, to cooperate in the implementation of their nationally determined contributions. The interpretation is that it is meant to cover all specific cases of cooperation in Article 6, and others that may emerge in the future.

2. Transfers of mitigation outcomes (Paragraphs 6.2-6.3). These paragraphs cover the concept that Parties, when involved in the specific case of cooperative approaches, which involve 
mitigation outcomes being transferred internationally, need to observe the guidance on accounting. What is particularly important is that these are international transfers of "mitigation outcomes" which can be produced from any mechanism/procedure/protocol, without any reference to the fact that the mechanism/procedure/protocol needs to operate under the authority of the COP.

3. Mechanism to contribute to mitigation and support sustainable development (Paragraphs 6.4-6.7). These paragraphs refer to the establishment of a mechanism to produce mitigation outcomes and support sustainable development, and which operates under the authority of the COP. It produces mitigation outcomes that can then be used to fulfil the NDC of another Party.

So to put this article into force or in the implementation stage, Trade in Climate-Smart Foreign Direct Investment (CSGTs) and climatesmart services cannot take place without prior investment. Both domestic investment and FDI are important in this regard. Investment is required to set up production capacity of CSGTs and to develop tools, machinery and technologies that are climatesmart. As domestic companies in developing countries often lack the capacity to invest in CSGTs due to a lack of capital or access to required technologies, FDI plays a fundamental role in bridging the gap.

While developing countries generally face constraints in developing a climate-smart.

Investment environment, early movers have a clear advantage in strengthening competitive advantages in this area.

The following concrete strategies, policies and measures to promote climate-smart investment can be identified as:

1. Mainstream FDI into climate-smart development strategies (mentioned above). Promoting FDI in CSGTs is not a panacea for climate change mitigation and adaptation by itself, but should be considered as part of a holistic approach to mitigating and adapting to climate change.

2. Create an enabling regulatory framework. Specific regulations need to be adopted and enforced to facilitate the entry, treatment and protection of climate smart FDI, including in the normally heavily regulated energy sector. Sufficient investment protection may be accorded under national laws, and investment contracts.
3. Pursue regional market integration in support of regional climate-smart value chains. Domestic markets are often too small for any investor, including climate smart investors, seeking efficiencies through expanding and strengthening regional and global value chains. The formation of these value chains can be supported through market integration, e.g., through RTAs or economic partnership agreements with wide and deep commitments to reduce tariffs and NTBs and to facilitate trade. In short, a favorable trade policy is essential for supporting climate-smart FDI.

4. Liberalize and deregulate energy markets (particularly the power sector). In many countries, entry restrictions for foreign investors are still high in many energy sectors. Liberalizing entry will be a larger incentive than financial incentives, and is part and parcel of establishing an enabling environment. In particular, the complete unbundling of generation, transmission and distribution functions to different commercial entities while promoting competition in all sectors can provide greater incentives for power suppliers to use clean energy technologies.

5. Provide specific incentives and privileges for climate-smart investment. A mix of appropriate fiscal and regulatory measures can be applied both to promote both climate-smart domestic investment and to attract climate-smart FDI. While tax incentives are normally not known to be a principal determinant for most types of quality FDI, it may help smooth the investment decision-making process as "icing on the cake". Tax rebates can be offered, although subsidies may perhaps be too much of a drain on the national budget and may violate WTO rules if they are linked to export performance. Instead, privileges can be offered both at the preestablishment and the post-establishment phases in the form of preferential treatment for foreign investors in getting licenses as well as access to land, labour, capital and other resources. Other measures include the accelerated depreciation of assets put in place to increase energy efficiency, and the lowering of withholding taxes on payments abroad for intellectual property licenses.

6. Avoid performance requirements. Some countries (e.g., China) have successfully imposed performance requirements such as local content requirements. However, many developing countries do not have a sufficiently developed domestic sector to warrant such requirements, which may affect the location 
choice of foreign investors who should be free to decide on their suppliers within the context of their global strategic management decisions. Such requirements may also violate TRIMS.

7. Provide necessary infrastructure and institutional framework for climate-smart FDI. Depending on whether climate-smart FDI is efficiency-seeking, resource seeking or marketseeking, transportation, communication and (clean) energy infrastructure is always required, but so are institutions that support climate smart business and development, including universities and $R \& D$ institutions. In particular, climate-smart TNCs can be a catalyst in boosting domestic R\&D and may be attracted by the availability of R\&D capacity, as well as qualified personnel in the host country. With regard to physical infrastructure, the establishment of climate-smart SEZs may be considered. Core elements of such SEZs include GHG mitigation targets, sustainable infrastructure, a smart incentives/policy regulatory framework and carbon finance China, India and the Republic of Korea are currently exploring the possibility of establishing "green" SEZs.

8. Promote and target specific climate-smart investment. Down from the policy level, the actual function of an investment promotion agency (IPA) or equivalent is to promote and target specific types of FDI. A special department or unit may be established in an IPA for the purpose of attracting climate-smart FDI. Such a department needs to be well-informed about investor needs and be client oriented.

\section{Carbon market and climate investment}

The carbon market consists of three main mechanisms: carbon taxes, carbon pricing and emission trading scheme. Each mechanism differs from the other in the mechanisms and methodologies required in its application, on the one hand, as well as the suitability of each mechanism with the economic conditions, especially in developing countries, on the other hand, and of course, in accordance with Article 6 of the Paris Agreement. One of the most important means of implementing greenhouse gas reduction commitments is carbon markets. But the question here is how well the mechanism fits into the economic situation in developing countries.

The choice of the appropriate mechanism depends on the flexibility of the economy in the country. The more flexible and flexible the economy, the easier it is to apply different mechanisms. It's better to introduce each mechanism.
4.1. Carbon pricing. Carbon pricing means that a specific price per tonne of emissions is set as if carbon emissions are one of the production inputs used in each product. Thus, each reduction in these emissions means a reduction in the cost of the product and a general reduction in the final product cost. Therefore, the application of this mechanism requires an advanced system to inventory emissions and follow-up systems and control and accurate verification within each economic unit, which is usually unavailable in developing countries.

4.2. Carbon taxes. It means imposing an emissions tax on each tonne of carbon dioxide above the normal rate of production (emission cap). This usually requires that the country's environmental legislation be amended and a ceiling on emissions should be set for each production process in different sectors. Such a mechanism is difficult to apply in developing countries, which are usually not flexible in their economies and are likely to increase inflation as a result of the end consumer's compliance with the tax. On the other hand, a carbon tax does not mean lower emissions because tax collection may not accompany such taxes towards projects to reduce carbon.

4.3. Emission trading scheme. It means the possibility of exchanging emissions between various economic sectors and establishing a market for the state that will be responsible for this exchange and similar to the financial markets. This mechanism is very similar to the CDM previously with the need for some legislative and logistical amendments. This mechanism is more suited to the conditions of developing countries as it offers opportunities to attract foreign direct investment, and it leaves new opportunities for work and towards low-carbon green technology.

From the previous view, the following is recommendation for developing countries to attract the foreign direct investment in climate change and sustainable development:

1. There is a close relationship between both sustainable development and climate change, so it is difficult to separate them. Therefore, addressing the implementation of either is closely related to the other.

2. That the potential negative impacts on the economies of developing countries in the implementation of emission reduction commitments under the Paris Agreement requires the implementation of Goal 17 of the Sustainable Development Goals and to cooperate in providing appropriate funding in accordance with the Paris Agreement.

3. The most appropriate way to finance greenhouse gas reduction is through direct foreign 
investment rather than direct economic assistance, but it is necessary to adjust the investment environment in developing countries to be more flexible and attractive for this kind of investment.

4. Despite the multiplicity of different types of carbon market mechanisms, the most suitable for developing countries is the mechanism of exchange of emissions to attract foreign direct investment and it requires a set of changes in the structure of the economy in developing countries to be more flexible.

\section{Conclusion}

From the previous presentation it is clear that although there are international commitments to reduce greenhouse gases, which some see as a burden on many countries, especially developing countries, however, it can create a new kind of investment, including cash flows, jobs and new economic activity. It also calls for more capacity-building and technology transfer in these areas, which means that the Paris Agreement on Climate Change should be activated and that developed countries should provide technical and financial support to developing countries to help them implement their greenhouse gas reduction commitments.

On the other hand, the developing countries should strive to modernize their economic management systems and amend some laws and regulations, whether financial or environmental, which provide a flexible and appropriate environment to activate carbon exchange.

The experience of the Kyoto Protocol in the Clean Development Mechanism (CDM) enables it to work on updating its scientific methodologies and increasing their flexibility, as well as developing an easy and flexible framework for carbon exchange, both within a single country and among a group of countries.

The need to find flexible financing mechanisms such as green bonds, green credit line and green economy.

In the end, the principle of shifting commitments into an incentive is what needs to be done for the success of carbon markets, whether national or international.

\section{References}

1. Bumpus, Adam. (2012). Fruitful design: the CDM. Retrieved from https://cdm.unfccc.int/about/dev_ben/CDMBenefits-2012

2. IPCC (2014). Climate Change 2014 Synthesis Report Summary for Policymakers, IPCC.

3. IPCC (2016). The dual relationship between climate change and Sustainable Development. Retrieved from www.ipcc.ch

4. Methodology for Integrated Environmental-Economic Analysis of GDP and Productivity, University of Minnesota.

5. Munasinghe, Mohan. (2009). Institute for Development (MIND). Climate change and sustainable development linkages: points of departure from the IPCC TAR.

6. OECD (2008). Sustainable Development and Climate Change: International and National Perspectives. Retrieved from http://www.oecd.org/newsroom/seminaronsustainabledevelopmentandclimatechangeinternationalandnationalpersp ectives.htm

7. Thomson, Peter. (2012). UNEP, financing sustainable development, moving from momentum to transformation in a time of turmoil.

8. UNFCCC (2013). Executive Board, annual report, Clean Development Mechanism.

9. United Nations (1992). Framework Convention on Climate Change (UNFCCC).

10. United Nations (1998). Kyoto Protocol.

11. United Nations (2015). Paris Agreement on Climate Change.

12. United Nations (2015). Sustainable Development Goals. 